\title{
Comparative study of different-fault-tolerant control strategies for three-phase induction motor
}

Toufik Roubache, Souad Chaouch, and Mohamed Said Nait Said

Msila University, Dept. of Electrical Engineering, 28000, Msila, Algeria. LSP-IE, Dept. of Electrical Engineering, Batna2, 05078, Batna, Algeria.

Received: 13 June 2021, Accepted: 16 June 2021

Published online: 12 July 2021.

\begin{abstract}
In this paper, we have studied a different fault tolerant control (FTC) strategies for a three-phase induction motor (3p-IM). Further we introduce Backstepping controller (BC) and Input-output linearization controller (IOLC). To provide a direct comparison between these FTCs approaches, the performances are evaluated using the control of 3p-IM under failures, variable speed, and variable parameters. A comparison between the two control strategies is proposed to prove the most robust one. The simulation results show the robustness and good performance of the fault tolerant control with Input-output linearization controller compared to one with Backstepping controller. The FTC with IOLC is more stable and robust against failures, load torque perturbation and speed reversion.
\end{abstract}

Keywords: Three-phase induction motor (3p-IM), Fault Tolerant Control (FTC), Input-output linearization controller, Backstepping controller.

\section{Introduction}

With the development of power electronics technology and control technology, three-phase induction motor has been widely applied in various industrial sectors and airline industry [1]. Due to its compact size, cost and reliability. 3p-IMs are subjected to various faults, such as stator short circuits, broken bars or rings, eccentricity, sensor and actuator faults, ...etc. As it is the case in $([2,3])$.

In recent years, fault-tolerant control (FTC) has begun to concern a wider range of industrial applications such as aerospace, automotive, nuclear power, manufacturing, etc. [4-6]. The passive FTC approach considers fault as a special kind of uncertainties, and consequently controllers are fixed and designed to be robust against a class of presumed faults. The remainder of this paper is organized as follows. Section 2 describes the mathematical faulty model of induction motor. In Section 3 and Section 4 the objective and design philosophy passive based FTCs strategies are described. Simulation results describe similarities and differences between them are summarized in Section 5. Finally, the conclusions are drawn in Section 6.

\section{Mathematic faulty model of IM and problem formulation}

The dynamic model of an induction motor in the stator reference frame can be described as:

$$
\dot{x}=A x+B u
$$

\footnotetext{
*Corresponding author e-mail: toufik.roubache@ gmail.com
} 
where $B$ is a constant matrix and $A$ is a nonlinear matrix.

$$
\left\{\begin{array}{l}
x=\left[\begin{array}{ll}
x_{1} x_{2} x_{3} x_{4}
\end{array}\right]^{T}=\left[i_{s \alpha} i_{s \beta} \Phi_{r \alpha} \Phi_{r \beta}\right]^{T} \\
u=\left[\begin{array}{ll}
u_{1} & u_{2}
\end{array}\right]^{T}=\left[\begin{array}{ll}
v_{s \alpha} & v_{s \beta}
\end{array}\right]^{T}
\end{array}\right.
$$

The objective of this section is to provide a robust PFTC fault design for the induction motor system affected by sensor faults and unknown bounded disturbances.

Let us consider the IM model given by the equations (1) and affected by sensor faults as [7]:

$$
\dot{x}=A x+B u+D_{f} \mathscr{F}
$$

where $\mathscr{F} \in \mathscr{R}$ is the sensor fault vector. Matrix $D_{f}$ is of appropriate dimension.

$$
\left\{\begin{array}{l}
D_{f}=\left[\begin{array}{llll}
1 & 0 & 0 & 0 \\
0 & 1 & 0 & 0
\end{array}\right]^{T} \\
\mathscr{F}=\left[\begin{array}{ll}
\mathscr{F}_{1} & \mathscr{F}_{2}
\end{array}\right]^{T}
\end{array}\right.
$$

The presence of electrical and/or mechanical faults generates asymmetry of the IM yielding some slot harmonics in the stator winding:

$$
\left\{\begin{array}{l}
x_{1} \rightarrow x_{1}+\mathscr{F}_{h 1} \\
x_{2} \rightarrow x_{2}+\mathscr{F}_{h 2}
\end{array}\right.
$$

where:

$$
\left\{\begin{array}{c}
\mathscr{F}_{h 1}=\sum_{i}^{n_{f}} A_{i} \sin \left(\omega_{i} t+\varphi_{i}\right) \\
\mathscr{F}_{h 2}=\sum_{i}^{n_{f}} A_{i} \cos \left(\omega_{i} t+\varphi_{i}\right) \\
\omega_{i}=2 \pi f_{i}+2 \pi f_{a}=2 \pi\left(f_{i}+f_{a}\right)
\end{array}\right.
$$

with: $n_{f}$ is faults number, $f_{i}$ is the characteristic frequency of the fault and $f_{a}$ is the fundamental frequency.

\section{Passive FTC based backstepping controller}

Backstepping control is an efficient method for nonlinear system [8]. This approach is presented in the form of steps for the determination of the control law given by the stator voltages of the IM [9-11]. The backstepping technique has been widely used in the design of speed controllers for induction motors [12-14].

\subsection{Speed controller design methodology}

The controller for the speed state can be designed in three steps.

Step 1. To solve speed tracking problem, the state tracking error variable can be defined as:

$$
\left\{\begin{array}{c}
e_{1}=\omega_{r e f}-\omega_{r} \\
e_{2}=x_{r e f}-x_{r}
\end{array}\right.
$$


where $\omega_{r e f}$ and $x_{r e f}$ are respectively rotor speed and rotor flux reference, $\omega_{r}$ is the actual rotor speed, $x_{r}$ is the actual rotor flux. For stabilizing the speed component, the derivative of (7) is given by:

$$
\left\{\begin{array}{l}
\dot{e}_{1}=\dot{\omega}_{r e f}-\frac{\rho}{J}\left(x_{2} x_{3}-x_{1} x_{4}\right)+\frac{T_{L}}{J} \\
\dot{e}_{2}=\dot{x}_{r e f}+2 T_{r} x_{r}-2 M T_{r}\left(x_{1} x_{3}+x_{2} x_{4}\right)
\end{array}\right.
$$

Step 2. Choose the following candidate Lyapunov function as:

$$
V_{1}=\frac{1}{2}\left(e_{1}^{2}+e_{2}^{2}\right)
$$

Step 3. The time derivative of Lyapunov function (9) can be obtained as:

$$
\begin{gathered}
\dot{V}_{1}=\left(e_{1} \dot{e}_{1}+e_{2} \dot{e}_{2}\right) \\
=e_{1}\left(\dot{\omega}_{r e f}-\frac{\rho}{J}\left(x_{2} x_{3}-x_{1} x_{4}\right)+\frac{T_{L}}{J}\right)+e_{2}\left(\dot{x}_{r e f}+2 T_{r} x_{r}-2 T_{r} M\left(x_{1} x_{3}+x_{2} x_{4}\right)\right.
\end{gathered}
$$

Thus, the tracking objectives will be satisfied if we choose:

$$
\left\{\begin{array}{l}
x_{1 r e f}=-\frac{J}{\rho x_{4}}\left(k_{1} e_{1}+\dot{\omega}_{r e f}+\frac{T_{L}}{J}\right)+\frac{1}{2 T_{r} M x_{3}}\left(k_{2} e_{2}+\dot{x}_{r}+2 T_{r} x_{r}\right) \\
x_{2 r e f}=\frac{J}{\rho x_{3}}\left(k_{1} e_{1}+\dot{\omega}_{r e f}+\frac{T_{L}}{J}\right)+\frac{1}{2 T_{r} M x_{4}}\left(k_{2} e_{2}+\dot{x}_{r}+2 T_{r} x_{r}\right)
\end{array}\right.
$$

Therefore, (10) can be rewritten as:

$$
\dot{V}_{1}=\left(-k_{1} e_{1}^{2}-k_{2} e_{2}^{2}\right)<0
$$

where $k_{1}$ and $k_{2}$ are positive design constants that determine the closed loop dynamics.

According to (12), the controls $x_{1 r e f}$ and $x_{2 r e f}$ in (11) are asymptotically stabilizing.

\subsection{Current controller design methodology}

Step 1. In this step, we define other errors $e_{3}$ and $e_{4}$ in the components of the stator currents and their references.

$$
\left\{\begin{array}{l}
e_{3}=x_{2 r e f}-x_{2} \\
e_{4}=x_{1 r e f}-x_{1}
\end{array}\right.
$$

So the dynamics of $e_{1}$ and $e_{2}$ can be obtained as:

$$
\left\{\begin{array}{l}
\dot{e}_{1}=-k_{1} e_{1}-\frac{\rho}{J}\left(e_{4} x_{4}-e_{3} x_{3}\right) \\
\dot{e}_{2}=-k_{2} e_{2}+2 M T_{r}\left(e_{4} x_{3}-e_{3} x_{4}\right)
\end{array}\right.
$$

The derivative errors dynamics in (13) are given by:

$$
\left\{\begin{array}{l}
\dot{e_{3}}=\dot{x}_{2 r e f}-\delta_{1}-b_{2} u_{2} \\
\dot{e_{4}}=\dot{x}_{1 r e f}-\delta_{2}-b_{1} u_{1}
\end{array}\right.
$$

with:

$$
\left\{\begin{array}{l}
\delta_{1}=-a_{1} x_{2}-a_{3} \omega_{r} x_{3}+a_{3} T_{r} x_{4} \\
\delta_{2}=-a_{1} x_{1}-a_{3} T_{r} x_{3}+a_{3} \omega_{r} x_{4}
\end{array}\right.
$$


Step 2. In this step we define the control laws, while final Lyapunov function based on all the errors of the speed, the rotor flux and the stator currents, such as:

$$
V_{2}=\frac{1}{2}\left(e_{1}^{2}+e_{2}^{2}+e_{3}^{2}+e_{4}^{2}\right)
$$

Step 3. The time derivative of $V_{2}$ is given by:

$$
\dot{V}_{2}=\left(e_{1} \dot{e_{1}}+e_{2} \dot{e_{2}}+e_{3} \dot{e_{3}}+e_{4} \dot{e_{4}}\right)
$$

According to (13) and (14), this equation can be rewritten as follows:

$$
\dot{V}_{2}=-k_{1} e_{1}^{2}-k_{2} e_{2}^{2}+e_{3}\left(\dot{x}_{2 r e f}-\delta_{1}-b_{2} u_{2}-2 M T_{r} x_{4}+\frac{\rho}{J} x_{3} e_{1}\right)+e_{4}\left(\dot{x}_{1 r e f}-\delta_{2}-b_{1} u_{1}+2 M T_{r} x_{3} e_{2}-\frac{\rho}{J} x_{4} e_{1}\right)
$$

where $u_{1}$ and $u_{2}$ are the actual control variables. If the stabilizing control law is defined as:

$$
\left\{\begin{array}{c}
u_{1}=\frac{1}{b_{1}}\left(\dot{x}_{1 r e f}+k_{4} e_{4}-\delta_{2}+2 M T_{r} x_{3} e_{2}-\frac{\rho}{J} x_{4} e_{1}\right) \\
u_{2}=\frac{1}{b_{2}}\left(\dot{x}_{2 r e f}+k_{3} e_{3}-\delta_{1}+2 M T_{r} x_{4} e_{2}+\frac{\rho}{J} x_{3} e_{1}\right) \\
k_{3}>0, k_{4}>0
\end{array}\right.
$$

Then, (15) can be expressed as:

$$
\left\{\begin{array}{l}
\dot{e}_{3}=-k_{3} e_{3}-\frac{\rho}{J} x_{3} e_{1}-2 M T_{r} x_{4} e_{2} \\
\dot{e}_{4}=-k_{4} e_{4}+\frac{\rho}{J} x_{4} e_{1}-2 M T_{r} x_{3} e_{2}
\end{array}\right.
$$

The choice of $k_{3}$ and $k_{4}$ as positive parameters can made $\dot{V}_{2}<0$, which indicates the tracking error will converge asymptotically to zero. The objective of BC for IM is completed.

\section{Passive FTC based input-output linearization controller}

For the induction motor case, by choosing the output functions as the flux square and rotor speed respectively as showing bellow:

$$
y=\left[\begin{array}{l}
y_{1} \\
y_{2}
\end{array}\right]=\left[\begin{array}{l}
h_{1} \\
h_{2}
\end{array}\right]=\left[\begin{array}{c}
\varphi_{r \alpha}^{2}+\varphi_{r \beta}^{2}=\varphi_{r}=x_{r} \\
\omega
\end{array}\right]
$$

Therefore, the output dynamics could be easily written as follows:

$$
y_{1}:\left\{\begin{array}{l}
\dot{h_{1}}(x)=L_{f} h_{1}(x)=2 a_{5} L_{m} f_{1}-2 a_{5} x_{r} \\
\ddot{h_{1}}(x)=L_{f}^{2} h_{1}(x)+L_{\mathrm{G}_{\alpha}} L_{f} h_{1}(x) u_{1}+L_{\mathrm{G}_{\beta}} L_{f} h_{1}(x) u_{2}
\end{array}\right.
$$

with:

$$
\begin{gathered}
\left\{\begin{array}{l}
L_{f}^{2} h_{1}(x)=2 a_{4} a_{5} L_{m} f_{3}-\left(2 a_{1} a_{4}+6 a_{4} a_{5}\right) f_{1}+2 a_{4} \omega f_{2}+\left(\frac{4}{T_{r}} a_{5}+2 a_{2} a_{4}\right) x_{r} \\
L_{\mathrm{G}_{\alpha}} L_{f} h_{1}(x)=2 a_{2} L_{r} x_{3} \\
L_{\mathrm{G}_{\beta}} L_{f} h_{1}(x)=2 a_{2} L_{r} x_{4}
\end{array}\right. \\
y_{2}:\left\{\begin{array}{c}
\dot{h_{2}}(x)=L_{f} h_{2}(x)=\frac{p L_{m}}{J L_{r}} f_{2}-\frac{C_{r}}{J} \\
\ddot{h_{2}}(x)=L_{f}^{2} h_{2}(x)+L_{\mathrm{G}_{\alpha}} L_{f} h_{2}(x) u_{1}+L_{\mathrm{G}_{\beta}} L_{f} h_{2}(x) u_{2}
\end{array}\right.
\end{gathered}
$$


with:

$$
\left\{\begin{array}{l}
L_{f}^{2} h_{2}(x)=\frac{p L_{m}}{J L_{r}} \omega f_{1}-\frac{p L_{m}}{J L_{r}}\left(a_{1}+a_{5}\right) f_{2}-\frac{p L_{m}^{2}}{J L_{r}^{2}} \frac{\omega}{\sigma L_{s}} x_{r} \\
L_{\mathrm{G}_{\alpha}} L_{f} h_{2}(x)=-\frac{p L_{m}}{J L_{r}} \frac{1}{\sigma L_{s}} x_{4} \\
L_{\mathrm{G}_{\beta}} L_{f} h_{2}(x)=\frac{p L_{m}}{J L_{r}} \frac{1}{\sigma L_{s}} x_{3}
\end{array}\right.
$$

where: $f_{1}=x_{1} x_{3}+x_{2} x_{4}, f_{2}=x_{2} x_{3}-x_{1} x_{4}, f_{3}=x_{1}^{2}+x_{2}^{2}, a_{1}=\frac{-R_{t}}{\sigma L_{s}}, a_{2}=\frac{L_{m}}{\sigma L_{s} L_{r} T_{r}}, a_{3}=\frac{L_{m}}{\sigma L_{s} L_{r}}, a_{4}=\frac{L_{m}}{T_{r}}, a_{5}=\frac{1}{T_{r}}$

Although the system dynamics order is five, the output dynamics have the order of four which implies the presence of an internal dynamics and the corresponding stability could be easily proven.

Using input-output feedback linearization, only the derivatives of the outputs are considered, we obtain:

$$
\left[\begin{array}{l}
\ddot{h_{1}} \\
\ddot{h_{2}}
\end{array}\right]=\left[\begin{array}{l}
L_{f}^{2} h_{1}(x) \\
L_{f}^{2} h_{2}(x)
\end{array}\right]+E(x)\left[\begin{array}{l}
u_{1} \\
u_{2}
\end{array}\right]
$$

with:

$$
E(x)=\left[\begin{array}{l}
L_{\mathrm{G}_{\alpha}} L_{f} h_{1}(x) L_{\mathrm{G}_{\beta}} L_{f} h_{1}(x) \\
L_{\mathrm{G}_{\alpha}} L_{f} h_{2}(x) L_{\mathrm{G}_{\beta}} L_{f} h_{2}(x)
\end{array}\right]=\left[\begin{array}{cc}
2 a_{2} L_{r} x_{3} & 2 a_{2} L_{r} x_{4} \\
-\frac{p L_{m}}{J L_{r}} \frac{1}{\sigma L_{s}} x_{4} & \frac{p L_{m}}{J L_{r}} \frac{1}{\sigma L_{s}} x_{3}
\end{array}\right]
$$

$\operatorname{Det}[E(x)]=2 \frac{a_{2} L_{r}}{\sigma L_{s}} x_{r}$. If $x_{r} \neq 0$, the matrix $E(x)$ is non-singular. By defining $v$ as the new control input for linear system of:

$$
v=\left[\begin{array}{l}
v_{1} \\
v_{2}
\end{array}\right]=\left[\begin{array}{l}
L_{f}^{2} h_{1}(x) \\
L_{f}^{2} h_{2}(x)
\end{array}\right]+E(x)\left[\begin{array}{l}
u_{1} \\
u_{2}
\end{array}\right]
$$

Main control equation can be defined as:

$$
\left[\begin{array}{l}
u_{1} \\
u_{2}
\end{array}\right]=E(x)^{-1}\left(\left[\begin{array}{l}
-L_{f}^{2} h_{1}(x) \\
-L_{f}^{2} h_{2}(x)
\end{array}\right]+\left[\begin{array}{l}
v_{1} \\
v_{2}
\end{array}\right]\right)
$$

As a result, the system control effort would be simplified to:

$$
\begin{aligned}
& v_{1}=\ddot{h_{1}}=\frac{d^{2} x_{r}}{d t^{2}}=k_{\varphi 1}\left(x_{r e f}-x_{r}\right)+k_{\varphi 2}\left(\frac{d x_{r e f}}{d t}-\frac{d x_{r}}{d t}\right)+\quad \frac{d^{2} x_{r e f}}{d t^{2}} \\
& v_{2}=\ddot{h_{2}}=\frac{d^{2} \omega}{d t^{2}}=k_{\omega 1}\left(\omega_{r e f}-\omega\right)+k_{\omega 2}\left(\frac{d \omega_{r e f}}{d t}-\frac{d \omega}{d t}\right)+\quad \frac{d^{2} \omega_{r e f}}{d t^{2}}
\end{aligned}
$$

The gains $k_{\varphi 1}, k_{\varphi 2}, k_{\omega 1}$ and $k_{\omega 2}$ are chosen by identification with a second order system by using the pole placement method.

\section{Simulation results}

In this section, some numerical simulations have been performed to validate the proposed FTC scheme (see. Figure.1).The induction motor parameters are given in the appendix. The closed-loop simulation results are reported in Figures below under both healthy and faulty conditions. On the other hand variations of $50 \%$ of the stator resistance $\left(R_{S}\right)$ and rotor resistance $\left(R_{r}\right)$ between the time $\mathrm{t}=3 \mathrm{~s}$ and $\mathrm{t}=4 \mathrm{~s}$ with variable speed reference are introduced. After the faults occurred at $t=1.5 \mathrm{~s}$. Two levels of simulation results will be presented here: firstly, Figure (2) show that the simulation results of PFTC based on Backstepping control, secondly, Figure (3) show that the simulation results of PFTC based on Input-output linearization controller. 


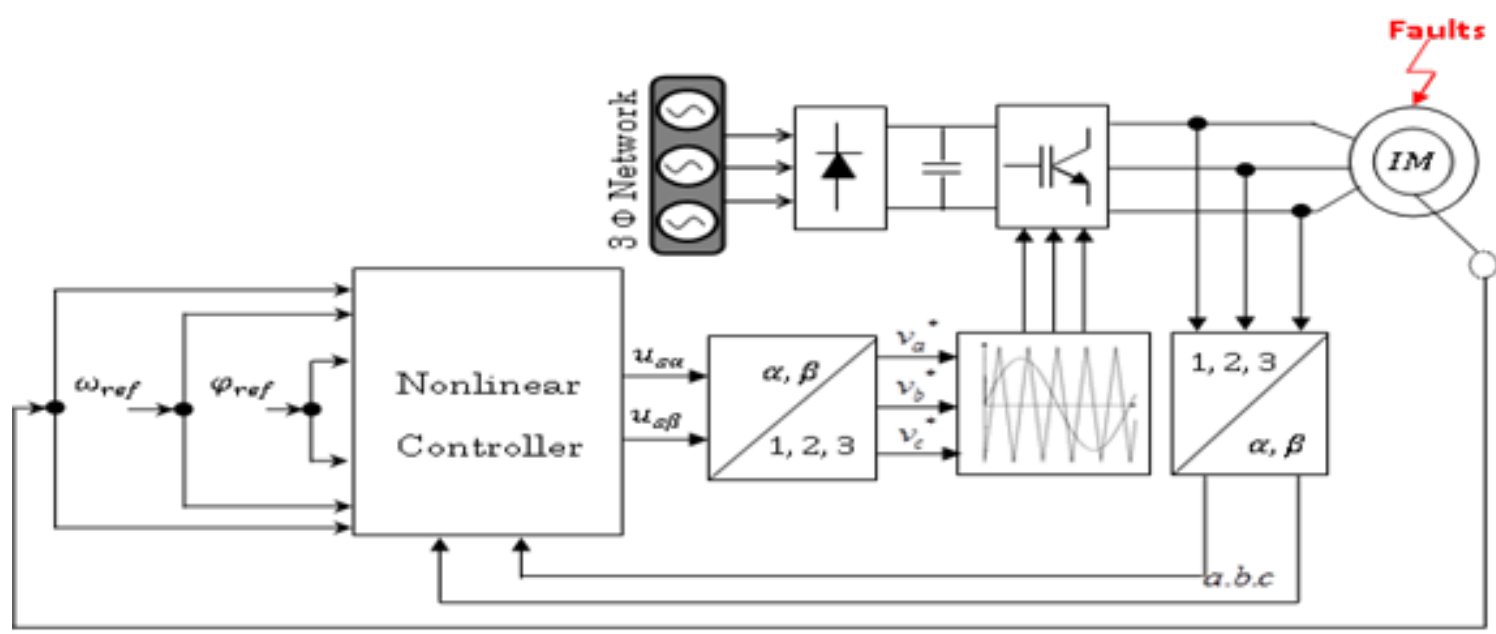

Fig. 1: Block diagram of the proposed passive fault tolerant

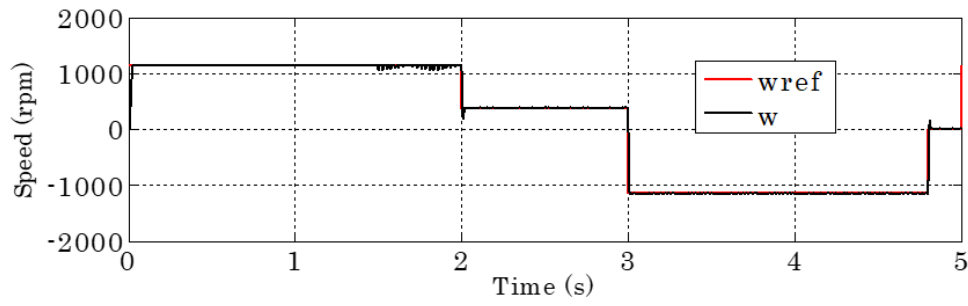

(a)

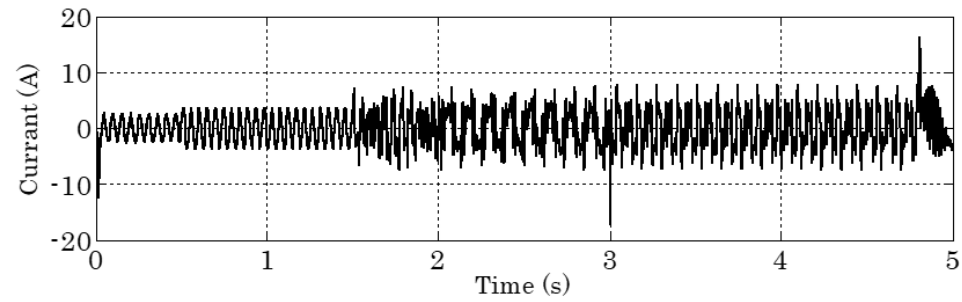

(b)

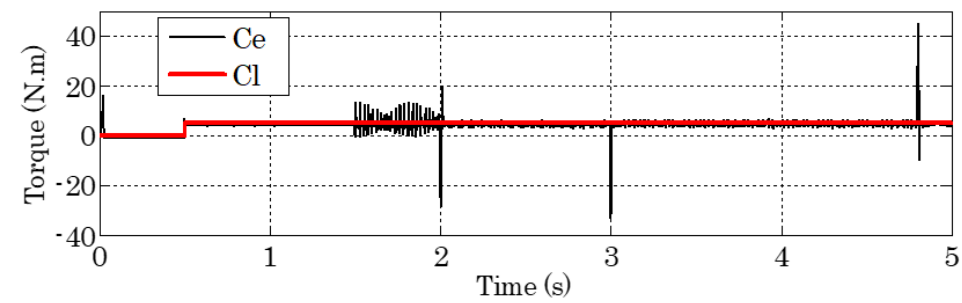

(c)

Fig. 2: PFTC strategy using Backstepping control: (a) Motor speed, (b) Stator Current, (c) Motor Torque (load torque is applied at $t=0.5 \mathrm{~s}$ and the actuator faults occurred at $t=1.5 \mathrm{~s}$ ). 


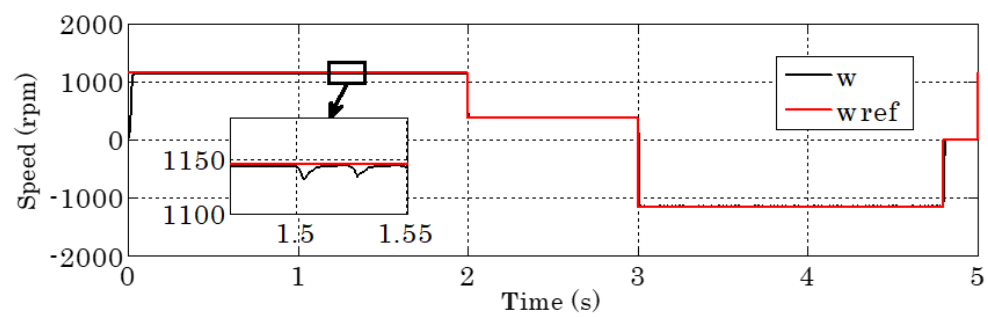

(a)

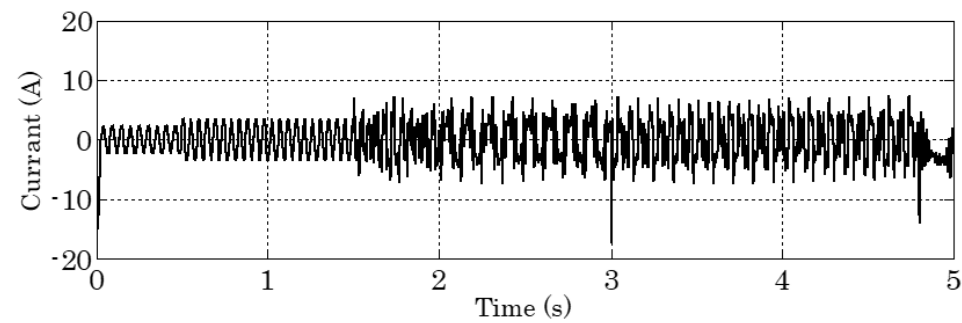

(b)

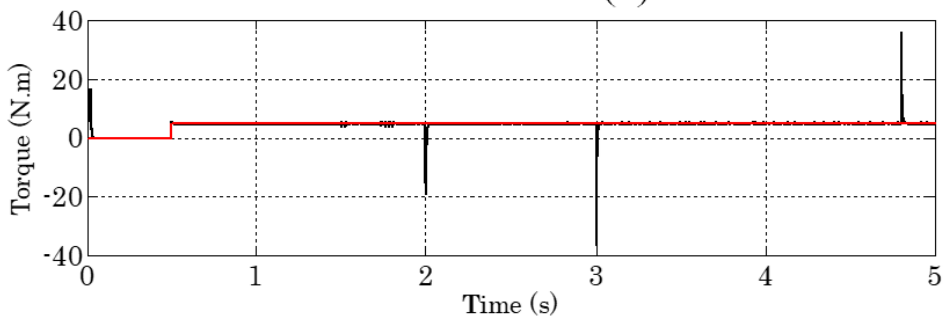

(c)

Fig. 3: PFTC strategy using Input-output linearization controller: (a) Motor speed, (b) Stator Current, (c) Motor Torque (load torque is applied at $t=0.5 \mathrm{~s}$ and the actuator faults occurred at $t=1.5 \mathrm{~s}$ ).

\section{Conclusion}

This paper dealt with a comparative study of fault tolerant control strategies, namely PFTC, Backstepping Controller (BC) and Input-output linearization controller (IOLC), for an induction motor. The study indicates that each approach has its own advantages and limitations. A passive FTCs approach is more flexible to deal with different types of faults, including failure scenarios beyond the design basis faults. For the PFTC, based IOLC simulation results demonstrate a good performance in the presence of fault. The global system drive is stable and robust against load perturbation, speed reversion, parameter variations and fault rejection. On conclusion, we can say that the PFTC based IOLC is more superior to PFTC based BC.

\section{Competing interests}

The authors declare that they have no competing interests.

\section{Authors' contributions}

All authors have contributed to all parts of the article. All authors read and approved the final manuscript. 


\section{References}

[1] A. Akincilar, Mathematical Model for Transporting the Arriving Passengers from the Airport to the City Centre. Acta physica polonica A Vol. 132, 2017. DOI:10.12693/APhysPolA.132.1214.

[2] C. Bonivento , A. Isidori ,L. Marconi, A. Paoli , Implicit fault tolerant control: Application to induction motors, IFAC, 35(1), pp. 299-304, 2002. https://doi.org/10.3182/20020721-6-ES-1901.00781

[3] C. Bonivento , A. Isidori ,L. Marconi and A. Paoli , Implicit fault tolerant control: application to induction motors. Automatica, 40, pp. 355-371, 2004. Doi:10.1016/j.automatica.2003.10.003

[4] M. Bruccoleri, M. Amico, and G. Perrone, Distributed intelligent control of exceptions in reconfigurable manufacturing systems, Int. J. Prod. Res., vol. 41, no. 7, pp. 1393-1412, May 2003. https://doi.org/10.1080/1352816031000075170

[5] R. Isermann, R. Schwarz, and S. Stolzl, Fault-tolerant drive-by-wire systems, IEEE Control Syst. Mag., vol. 22, no. 5, pp. 64-81, Oct. 2002.Doi: 10.1109/MCS.2002.1035218

[6] M. G. Mehrabi, A. G. Ulsoy, Y. Koren, and P. Heytler, Trends and perspectives in flexible and reconfigurable manufacturing systems, J. Intell. Manuf., vol. 13, no. 2, pp. 135-146, 2002.

[7] T. Roubache, S. Chaouch, Ms. Nait-Said, Backstepping design for fault detection and FTC of an induction motor drives-based Evs, Automatika 57(3): 736-748. http://dx.doi.org/10.7305/automatika. 2017.02.1733.

[8] C-X. Chen, Y-X. Xie, Y-H. Lan, Backstepping Control of Speed Sensorless Permanent Magnet Synchronous Motor Based on Slide Model Observer Speed controller design methodology, International Journal of Automation and Computing, 12(2), April 2015, 149-155. Doi: 10.1007/s11633-015-0881-2.

[9] H.T. Lee, L.C. Fu, and F.L. Lian, Sensorless adaptive backstepping speed control of induction motor, In Proc IEEE Conference on Decision \& Control, USA, December 2006, pp. 1252-1257. Doi: 10.1109/CDC.2006.377160

[10] H. Tan et al., Adaptive backstepping control of induction motor with uncertainties, In Proceedings of the IEEE ACC'99, San Diago (USA), vol. 1, pp. 1-5, June 1999. Doi: 10.1109/ACC.1999.782729

[11] H. Hwang, Y. Park, K. Yang, Robust Adaptive Backstepping Control for Efficiency Optimization of Induction Motors with uncertainties, IEEE International Symposium on Industrial Electronics, 2008, pp. 878-883. Doi: 10.1109/ISIE.2008.4677060

[12] R. Trabelsia, R. Khedherb, A. Mimounic, M. M'sahli, Backstepping Control for an Induction Motor Using an Adaptive Sliding Rotor Flux Observer, In: Electric Power Systems Research, Vol. 93, 2012, pp. 1-15. https://doi.org/10.1016/j.epsr.2012.06.004

[13] I. K. Bousserhane, A. Hazzab, M. Rahli, B. Mazari, M. Kamli, Position Control of Linear Induction Motor using an Adaptive Fuzzy Integral-Backstepping Controller, Serbian journal of electrical engineering, Vol. 3, no. 1, pp. 1-17, June 2006. Doi: 10.2298/SJEE0601001B

[14] S. Chaouch, Ms. Nait-Said, M. Makouf, A. Cherifi, Backstepping Control Based on Lyapunov Theory for Sensorless Induction Motor with Sliding Mode Observer, In: Ariser Journal- Sciences, Vol. 4, No. 1, January 2008, pp. 19-27. 